\title{
openheart Transfer of residents to hospital prior to cardiac death: the influence of nursing home quality and ownership type
}

\author{
Gabriella M Anic, ${ }^{1}$ Elizabeth Barnett Pathak, ${ }^{2}$ Jean Paul Tanner, ${ }^{1}$ Michele L Casper, ${ }^{3}$ \\ Laurence G Branch ${ }^{4}$
}

To cite: Anic GM, Pathak EB, Tanner JP, et al. Transfer of residents to hospital prior to cardiac death: the influence of nursing home quality and ownership type. Open Heart 2014:1:e000041.

doi:10.1136/openhrt-2014000041

Received 21 January 2014 Revised 24 June 2014 Accepted 21 July 2014

\section{(a) CrossMark}

${ }^{1}$ Department of Epidemiology and Biostatistics, University of South Florida, Tampa, Florida, USA

${ }^{2}$ Department of Internal Medicine, Morsani College of Medicine, University of South Florida, Tampa, Florida, USA ${ }^{3}$ Centers for Disease Control and Prevention, Atlanta, Georgia, USA

${ }^{4}$ Department of Health Policy and Management, University of South Florida, Tampa, Florida, USA

Correspondence to Dr Elizabeth B Pathak; epathak@health.usf.edu

\section{ABSTRACT}

Objectives: We hypothesised that among nursing home decedents, nursing home for-profit status and poor quality-of-care ratings, as well as patient characteristics, would lower the likelihood of transfer to hospital prior to heart disease death.

Methods: Using death certificates from a large metropolitan area (Tampa Florida Metropolitan Statistical Area) for 1998-2002, we geocoded residential street addresses of heart disease decedents to identify 2172 persons who resided in nursing homes $(n=131)$ at the time of death. We analysed decedent place of death as an indicator of transfer prior to death. Multilevel logistic regression modelling was used for analysis. Cause of death and decedent characteristics were obtained from death certificates. Nursing home characteristics, including state inspector ratings for multiple time points, were obtained from Florida's Agency for Healthcare Administration.

Results: Nursing home for-profit status, level of nursing care and quality-of-care ratings were not associated with the likelihood of transfer to hospital prior to heart disease death. Nursing homes $>5$ miles from a hospital were more likely to transfer decedents, compared with facilities located close to a hospital. Significant predictors of no transfer for nursing home residents were being white, female, older, less educated and widowed/unmarried.

Conclusions: In this study population, contrary to our hypotheses, sociodemographic characteristics of nursing home decedents were more important predictors of no transfer prior to cardiac death than quality rankings or for-profit status of nursing homes.

\section{INTRODUCTION}

Little research has focused on mortality among nursing home residents, despite widespread evidence of substandard quality of care (QOC) in many nursing homes in the USA. ${ }^{1}$ Unspoken cultural beliefs that mortality among nursing home residents is 'inevitable' or 'unpreventable' may be widespread, even among healthcare providers. However, in the case of heart disease-the leading

\section{KEY MESSAGES}

What is already known about this subject?

- For-profit nursing homes in the USA are known to provide lower quality of care than non-profit nursing homes. However, there has been little research on nursing home mortality, including determinants of hospital transfer and place of death.

What does this study add?

- Contrary to our hypotheses, nursing home quality indicators and for-profit status did not impact likelihood of transfer of residents to hospital prior to cardiac death. Rather, individual patient characteristics were most important, with older, less educated, widowed women least likely to be transferred prior to cardiac death.

How might this impact on clinical practice?

- Timely medical intervention can prevent cardiac death even among very elderly patients. Clear communication between physicians and patients and families, including do-not-rescusitate orders if desired, is necessary to ensure that end-of-life care and place of death are consistent with patient preferences.

cause of death in the $\mathrm{USA}^{2}$ and a common morbidity among nursing home residents ${ }^{3}-$ advances in medical treatment and cardiac care have markedly reduced case death rates in recent years. ${ }^{4}$ Benefits of aggressive treatment are documented even among the very old. ${ }^{56}$ Appropriate and timely hospitalisation of nursing home residents with heart disease can reduce case fatality. It follows that cardiac deaths that occur in nursing homes without transport to hospital may represent, in some cases at least, lost opportunities for life-saving medical intervention. However, nursing home residents and their families may prefer to avoid hospitalisation and medical interventions at the end of life. Advanced directives such as do-not-resuscitate (DNR) or do-not-hospitalise $(\mathrm{DNH})$ orders can influence the decision 
to hospitalise a nursing home resident. Residents with a DNH order are less than half as likely to be hospitalised compared with residents without this advanced directive. ${ }^{7}$ Unfortunately, DNR and DNH orders are not common; of all nursing home residents covered by Medicare in 2001, 32\% had a DNR order and only $2 \%$ had a DNH order. $^{8}$

There were a total of 18000 nursing homes in operation in 1999 in the USA, providing shelter and care to 1.6 million people. ${ }^{9}$ The majority of nursing homes were for-profit $(67 \%)$, part of a corporate chain $(60 \%)$ and certified to receive reimbursement from the federal insurance plans, Medicare and Medicaid $(82 \%){ }^{9}$ Previous research has found that nursing home residents are less likely to be transferred to a hospital if they are female,${ }^{1011}$ cognitively impaired, ${ }^{10}$ have congestive heart failure $^{1011}$ or have a DNR order. ${ }^{8}{ }^{10}$ Residents are more likely to have a DNR if they are older, or have a primary diagnosis of cardiovascular disease or congestive heart failure on admission to the nursing home. ${ }^{8}$

A national nursing home mortality surveillance system does not exist in the USA. Because for-profit facilities have been shown to provide poorer QOC than nonprofit nursing homes, ${ }^{12} 13$ we hypothesised that for-profit ownership and lower QOC (as reflected in state inspectors' QOC ratings) resulted in a greater likelihood of residents who died from heart disease dying in their nursing home versus a hospital.

To the best of our knowledge, no previous studies have examined the predictors of lack of transfer to hospital among nursing home decedents prior to dying from heart disease. Additional nursing home characteristics we investigated were intermediate care versus skilled nursing care, and distance of the nursing home to the nearest acute care hospital. Based on previous research findings in noninstitutionalised populations, ${ }^{14}$ we hypothesised that the following individual characteristics would decrease the likelihood of transfer: older age, female gender, white race, being unmarried, less education and a mention of dementia or senility on the death certificate.

\section{METHODS}

\section{Study population}

Our study population comprised patients aged 60 years and older who resided in nursing homes in the Tampa-St. Petersburg-Clearwater Metropolitan Statistical Area (MSA) (hereafter referred to as the Tampa MSA) and died from heart disease during 1998-2002. The Tampa Bay area has a racially and ethnically diverse population of approximately 2.4 million people. In $2000,10.4 \%$ of the population reported themselves Hispanic and $10.2 \%$ of the population identified as African-American. ${ }^{15}$ The area is a mix of urban, suburban and rural geography, and a popular retirement destination, with $23.7 \%$ of residents aged 60 years and older.
Decedents were identified using death certificate data obtained from the Florida Office of Vital Statistics. Decedent characteristics included age, gender, race, marital status and highest educational attainment. Death certificates do permit indication of 'nursing home' as a place of death; however, nursing home residents who die elsewhere cannot be identified from death certificates. In this study, we used a unique geocoded dataset that linked decedent addresses to nursing home locations to investigate transport to hospital prior to cardiac death.

As part of a larger study, we geocoded approximately 49000 heart disease deaths that occurred in the study area from 1998 to 2002. The address of each nursing home was geocoded after all the nursing homes in the area were identified. To identify nursing home decedents, we matched the residential address information on the death certificate to the nursing home addresses. Decedents whose address matched an address of a nursing home were considered to be a nursing home resident. We manually checked all decedent addresses that were within 0.1 miles of each nursing home to identify additional nursing home residents who had errors in their address data.

The underlying cause of death reported on the death certificate was used to identify heart disease deaths. Deaths that occurred in 1998 were coded with International Classification of Disease (ICD) 9 codes and deaths from 1999 to 2002 were coded with ICD 10 codes. Heart disease deaths included all of the following: chronic rheumatic heart disease (ICD 9 codes 393-398; ICD 10 codes I05-I09), hypertensive disease (ICD 9 codes 401-405; ICD 10 codes I10-I15), ischaemic heart disease (ICD 9 codes 410-414; ICD 10 codes I20-I25), pulmonary embolism and infarction (ICD 9 code 415.1; ICD 10 code I26.9), pulmonary heart disease (ICD 9 code 416.9; ICD 10 codes I27.0, I27.9) and heart failure and other forms of heart disease (ICD 9 codes 420-429; ICD 10 codes I30-I52).

\section{Nursing home characteristics}

The nursing homes in our study area were identified from the 1998 and 2001 Florida Agency for Healthcare Administration (AHCA) Nursing Home Guide. AHCA is responsible for regulating healthcare facilities in Florida. We excluded a small number of nursing homes that were government-owned, hospital-based or part of a continuing care retirement community, because we could not use geocoding to match cardiac decedents to these facilities. After exclusions, 131 nursing homes were included in this analysis. The 2001 Nursing Home Guide was used to compile data on ownership type, number of beds, minimum daily charge, payment forms accepted, special services offered (eg, special accommodations for patients with Alzheimer's disease), and annual inspection ratings for each nursing home.

AHCA performs annual inspections to assess whether a nursing home that accepts Medicare (government insurance for the elderly) or Medicaid (government insurance for low-income persons) meets federal 
standards of care in eight categories: (1) QOC-overall care standards such as preventing pressure ulcers and proper food preparation; (2) quality of life (QOL) treating residents with dignity, and accommodating residents' needs and preferences; (3) administrationaccurate assessment of residents' health status and developing adequate care plans for residents; (4) nutrition and hydration-maintaining residents' nutrition status, and providing sufficient fluid intake; (5) restraints and abuse-preventing verbal, mental or physical abuse; (6) pressure ulcers-prevention and treatment of pressure ulcers; (7) resident decline-ensuring activities of daily living (ADLs) do not decline and providing proper support to ADL-dependent residents and (8) resident dignity-allowing residents to freely choose their activities, visitors and social activities. Nursing homes receive an inspection score for each category based on how they rank relative to other nursing homes in the same region of Florida. Ratings are scored from 1 to 5, with a higher score indicating a better rating.

Nursing homes were classified into four groups based on ownership type (for-profit vs non-profit) and skilled versus intermediate care: (1) non-profit skilled care nursing facility; (2) for-profit skilled care nursing facility; (3) non-profit intermediate care nursing facility; (4) forprofit intermediate care nursing facility. Skilled-care nursing homes are required to have a registered nurse $(\mathrm{RN})$ onsite $24 \mathrm{~h}$ per day, while intermediate care nursing facilities typically have an $\mathrm{RN}$ onsite for $8 \mathrm{~h}$ a day.

Finally, we assessed whether proximity to a hospital was associated with no transfer. After identifying all hospitals with emergency departments, we used GIS to conduct a street route analysis to calculate the driving distance from each nursing home to the nearest hospital.

\section{Outcome}

The outcome in this study was dichotomous: no transfer prior to heart disease death versus transfer to hospital prior to heart disease death. The place of death information on the death certificate was used to classify a decedent's transfer status. A decedent was considered to be transferred before death if their place of death was reported as (1) emergency room/outpatient, (2) inpatient in the hospital, (3) dead on arrival at the hospital or (4) died at a hospital but status (outpatient or inpatient) unknown. Decedents who died in the nursing home were classified as not transferred.

\section{Analysis}

Hierarchical (multilevel) logistic regression models were used to identify three types of independent effects on our outcome variable (no transfer vs transfer). First, random effects were estimated and these correspond to the contribution of each individual nursing home $(\mathrm{n}=131)$ to the overall variance in the model. Second, fixed effects of nursing home characteristics were estimated. Third, fixed effects of individual patient (decedent) characteristics were estimated. The logit link in the June 2006 release of PROC GLIMMIX in SAS V.9.1.3 was used to run the models.

First, a null model was fit with no fixed effects and random intercepts for the 131 nursing homes. The following equation was used for the null model:

$$
\log \left[\mathrm{p}_{\mathrm{ij}} /\left(1-\mathrm{p}_{\mathrm{ij}}\right)\right]=\beta_{0}+\mathrm{u}_{\mathrm{j}}
$$

where $\mathrm{p}_{\mathrm{ij}}$ is the probability of the ith individual in the jth nursing home dying without transfer to the hospital and $u_{j}$ the random effect at the nursing home level. Next, we added the nursing home characteristic variables as fixed effects, using the following model:

$$
\begin{aligned}
\log \left[\mathrm{p}_{\mathrm{ij}} /\left(1-\mathrm{p}_{\mathrm{ij}}\right)\right]= & \beta_{0}+\beta_{1} \text { nursing home } \text { category }_{\mathrm{ij}} \\
& +\beta_{2} 2.5-5 \text { miles to hospital }_{\mathrm{ij}} \\
& +\beta_{3}>5 \text { miles to hospital }_{\mathrm{ij}} \\
& +\beta_{4}{\text { QOC } \text { rating }_{\mathrm{ij}}+\mathrm{u}_{\mathrm{j}}}
\end{aligned}
$$

where nursing home category, $2.5-5$ miles to hospital, $>5$ miles to hospital and QOC rating were dummy-coded variables for the nursing home level predictors. To look at demographic predictors, we ran a model with random intercepts for nursing homes and fixed effects for decedent characteristics including age, gender, race/ethnicity, marital status, education and the presence of a dementia or senility-related contributory cause of death:

$$
\begin{aligned}
\log \left[\mathrm{p}_{\mathrm{ij}} /\left(1-\mathrm{p}_{\mathrm{ij}}\right)\right]= & \beta_{0}+\beta_{1} \text { age } 70-79_{\mathrm{ij}} \\
& +\beta_{2} \text { age } 80-89_{\mathrm{ij}}+\beta_{3} \text { age } 90-99_{\mathrm{ij}} \\
& +\beta_{4} \text { age } \geq 100_{\mathrm{ij}}+\beta_{5} \text { female }_{\mathrm{ij}} \\
& +\beta_{6} \text { Black or Hispanic }_{\mathrm{ij}} \\
& +\beta_{7} \text { non-married }_{\mathrm{ij}} \\
& +\beta_{8} \text { no high school degree }_{\mathrm{ij}} \\
& +\beta_{9} \text { senility }_{\mathrm{ij}}+\mathrm{u}_{\mathrm{j}}
\end{aligned}
$$

Finally, a full model was run that contained nursing home random intercepts and fixed effects for all nursing home and decedent characteristics:

$$
\begin{aligned}
\log \left[\mathrm{p}_{\mathrm{ij}} /\left(1-\mathrm{p}_{\mathrm{ij}}\right)\right]= & \beta_{0}+\beta_{1} \text { NH category } \\
& +\beta_{2} \text { distance to hospital }_{\mathrm{ij}} \\
& +\beta_{3} \text { QOC rating }_{\mathrm{ij}}+\beta_{4} \text { age } 70-79_{\mathrm{ij}} \\
& +\beta_{5} \text { age } 80-89_{\mathrm{ij}}+\beta_{6}{\text { age } 90-99_{\mathrm{ij}}} \\
& +\beta_{7} \text { age } \geq 100_{\mathrm{ij}}+\beta_{8} \text { female }_{\mathrm{ij}} \\
& +\beta_{9} \text { Black or Hispanic } \mathrm{ij}_{\mathrm{ij}} \\
& +\beta_{10} \text { non-married } \\
& +\beta_{11} \text { no high school degree } \\
& +\beta_{12} \text { senility }_{\mathrm{ij}}+\mathrm{u}_{\mathrm{j}}
\end{aligned}
$$


Table 1 Nursing home characteristics, Tampa MSA 1998-2002

\begin{tabular}{|c|c|c|c|c|c|}
\hline & $\begin{array}{l}\text { All nursing } \\
\text { homes } \\
\%(n)\end{array}$ & $\begin{array}{l}\text { Skilled } \\
\text { nursing } \\
\text { facility, } \\
\text { non-profit } \\
\%(n)\end{array}$ & $\begin{array}{l}\text { Skilled } \\
\text { nursing } \\
\text { facility, } \\
\text { for-profit } \\
\% \text { (n) }\end{array}$ & $\begin{array}{l}\text { Intermediate } \\
\text { nursing facility, } \\
\text { non-profit } \\
\% \text { (n) }\end{array}$ & $\begin{array}{l}\text { Intermediate } \\
\text { nursing facility, } \\
\text { for-profit } \\
\% \text { (n) }\end{array}$ \\
\hline Number of nursing homes & 131 & 11 & 75 & 12 & 33 \\
\hline Owned by a chain & $42.8(56)$ & $18.2(2)$ & $57.3(43)$ & $25.0(3)$ & $24.2(8)$ \\
\hline $\begin{array}{l}\text { Special accommodations made for } \\
\text { patients with Alzheimer's disease } \\
\text { and dementia (eg, separate living } \\
\text { quarters) }\end{array}$ & $40.5(53)$ & $72.7(8)$ & $40.0(30)$ & 33.3 ( 4$)$ & $33.3(11)$ \\
\hline $\begin{array}{l}\text { Able to provide care for } \\
\text { ventilator-dependent residents }\end{array}$ & $7.6(10)$ & $9.1(1)$ & $12.0(9)$ & $0.0(0)$ & $0.0(0)$ \\
\hline \multicolumn{6}{|c|}{ Distance from nursing home to nearest hospital (miles) } \\
\hline$<2.5$ & $58.0(76)$ & $45.5(5)$ & $61.3(46)$ & $41.7(5)$ & $60.6(20)$ \\
\hline $2.5-5$ & $28.2(37)$ & 27.3 ( 3$)$ & $24.0(18)$ & $41.7(5)$ & $33.3(11)$ \\
\hline$>5$ & $13.7(18)$ & 27.3 ( 3$)$ & $14.7(11)$ & 16.7 ( 2) & $6.1(2)$ \\
\hline Total beds (mean, SD) & $118.5,51.1$ & $137.6,73.9$ & $129.1,39.7$ & $109.6,56.7$ & $91.0,54.4$ \\
\hline Private beds (mean, SD) & $9.1,13.6$ & $9.2,13.8$ & $9.4,12.1$ & $16.3,27.6$ & $5.8,7.6$ \\
\hline $\begin{array}{l}\text { Lowest daily charge for a bed } \\
\text { (mean, SD) }\end{array}$ & $124.0,20.2$ & $141.8,37.2$ & $123.0,11.5$ & $123.9,11.4$ & $120.5,27.3$ \\
\hline \multicolumn{6}{|c|}{ Percentage ${ }^{\star}$ of decedents who resided in a $\mathrm{NH}$ with a low rating $(1,2)$ on the AHCA inspection categoriest } \\
\hline Quality of care & $35.2(764)$ & $10.4(37)$ & $55.3(441)$ & 16.6 ( 49) & $32.8(237)$ \\
\hline Quality of life & $43.9(953)$ & $10.4(37)$ & $43.2(345)$ & $50.0(148)$ & $58.5(423)$ \\
\hline Administration & $36.9(801)$ & $27.9(99)$ & $48.9(390)$ & $10.5(31)$ & $38.9(281)$ \\
\hline Nutrition and hydration & $27.7(602)$ & $15.8(56)$ & $42.4(338)$ & $11.1(33)$ & $24.2(175)$ \\
\hline Abuse and restraint & $36.9(802)$ & $6.5(23)$ & 38.0 (303) & $49.0(145)$ & $45.8(331)$ \\
\hline Ulcer & $31.6(687)$ & $10.4(37)$ & 42.9 (342) & $53.0(157)$ & $20.9(151)$ \\
\hline Dignity & $41.6(903)$ & $22.5(80)$ & $55.4(442)$ & $27.4(81)$ & $41.5(300)$ \\
\hline Decline & $38.3(831)$ & $34.4(122)$ & 45.4 (362) & $42.2(125)$ & $30.7(222)$ \\
\hline
\end{tabular}

${ }^{*}$ Denominator is all decedents in that category of $\mathrm{NHs}$.

†See the Methods section for description of rating scores and inspection categories.

AHCA, Agency for Healthcare Administration; $\mathrm{NH}$, nursing home.

\section{RESULTS}

Characteristics of the 131 nursing homes in our metropolitan study area are presented in table 1 . The most prevalent nursing homes were for-profit skilled-care nursing facilities $(57.3 \%, \mathrm{n}=75)$, followed by for-profit intermediate care nursing facilities $(25.2 \%, \mathrm{n}=33)$. Overall, nursing homes had an average of 119 beds and a minimum daily charge of $\$ 124$. Almost half of the nursing homes were owned by a chain $(42.8 \%)$ and were located $<2.5$ miles from the nearest hospital $(58 \%)$. Almost half of the nursing homes had special accommodation for residents with dementia or Alzheimer's disease $(40.5 \%)$. Close to half of all decedents lived in a nursing home that scored poorly on the 2001 annual inspection for QOL $(43.9 \%)$ and resident dignity $(41.6 \%)$.

We identified 2172 nursing home residents aged 60 years and older who died from heart disease during 1998-2002 in the Tampa MSA (table 2). Of these decedents, $70.9 \%$ were not transferred prior to dying. The most common place of death was in a nursing home $(63.9 \%)$ followed by hospital inpatient (24.9\%). Almost half of all decedents were aged 90 years or older at the time of death $(44.4 \%)$. The majority of decedents were female $(70.0 \%)$, white non-Hispanic $(93.1 \%)$, high school graduates $(75.4 \%)$ and not currently married $(85.5 \%)$. The majority of unmarried decedents $(77.9 \%)$ were widowed. No transfer prior to cardiac death was most common among decedents in an intermediate care non-profit nursing facility $(73.3 \%)$. This nursing home category also had the highest proportion of decedents aged 90 years or older $(50.4 \%)$. The proportion of Black or Hispanic decedents was highest in intermediate care for-profit nursing facilities (9.7\%). Finally, skilled for-profit nursing facilities had the highest proportion of decedents who were female $(74.2 \%)$, not currently married $(89.3 \%)$, had less than a high school diploma $(29.5 \%)$ and a dementia or senility-related contributory cause of death $(13.2 \%)$.

Table 3 presents results from the multilevel models. We chose to include the QOC rating in the multilevel models because it was the rating category most strongly associated with the outcome and it represented an overall assessment of care in the nursing homes. As previous research suggests, there are differences in QOC in for-profit versus non-profit and skilled care versus 
Table 2 Characteristics of cardiac decedents by nursing home category, Tampa Bay MSA, 1998-2002

\begin{tabular}{|c|c|c|c|c|c|}
\hline & $\begin{array}{l}\text { Total } \\
(n=2172)\end{array}$ & $\begin{array}{l}\text { Skilled nursing } \\
\text { facility, } \\
\text { non-profit } \\
(n=355)\end{array}$ & $\begin{array}{l}\text { Skilled nursing } \\
\text { facility, } \\
\text { for-profit } \\
(n=798)\end{array}$ & $\begin{array}{l}\text { Intermediate } \\
\text { nursing facility, } \\
\text { non-profit }(n=296)\end{array}$ & $\begin{array}{l}\text { Intermediate } \\
\text { nursing facility, } \\
\text { for-profit }(n=723)\end{array}$ \\
\hline \multicolumn{6}{|l|}{ Age } \\
\hline$<70$ & $3.9 \%(85)$ & $0.9 \%(3)$ & $3.9 \%(31)$ & $2.0 \%(6)$ & $6.2 \%(45)$ \\
\hline $70-79$ & $11.9 \%(259)$ & $7.9 \%(28)$ & $12.4 \%(99)$ & $6.8 \%(20)$ & $15.5 \%(112)$ \\
\hline$\geq 100$ & $3.1 \%(68)$ & $3.9 \%(14)$ & $3.0 \%(24)$ & $4.4 \%(13)$ & $2.4 \%(17)$ \\
\hline \multicolumn{6}{|l|}{ Gender } \\
\hline Male & $30.0 \%(651)$ & $33.0 \%(117)$ & $25.8 \%(206)$ & $30.7 \%(91)$ & $32.8 \%(237)$ \\
\hline Female & $70.0 \%(1521)$ & $67.0 \%(238)$ & $74.2 \%(592)$ & $69.3 \%(205)$ & $67.2 \%(486)$ \\
\hline \multicolumn{6}{|l|}{ Race/ethnicity } \\
\hline White non-Hispanic & $93.1 \%(2022)$ & $99.4 \%(353)$ & $91.6 \%(731)$ & $96.3 \%(285)$ & $90.3 \%(653)$ \\
\hline Married & $12.0 \%(261)$ & $14.4 \%(51)$ & $9.0 \%(72)$ & $18.6 \%(55)$ & $11.5 \%(83)$ \\
\hline Divorced & $9.1 \%(197)$ & $5.9 \%(21)$ & $10.5 \%(84)$ & $4.4 \%(13)$ & $10.9 \%(79)$ \\
\hline Never married & $7.8 \%(170)$ & $6.8 \%(24)$ & $7.1 \%(57)$ & $7.8 \%(23)$ & $9.1 \%(66)$ \\
\hline Widowed & $68.6 \%(1489)$ & $72.4 \%(257)$ & $71.7 \%(572)$ & $67.9 \%(201)$ & $63.5 \%(459)$ \\
\hline Unknown & $2.5 \%(55)$ & $0.6 \%(2)$ & $1.6 \%(13)$ & $1.4 \%(4)$ & $5.0 \%(36)$ \\
\hline \multicolumn{6}{|l|}{ Education } \\
\hline$<$ High school & $24.7 \%(537)$ & $18.0 \%(64)$ & $29.5 \%(235)$ & $15.9 \%(47)$ & $26.4 \%(191)$ \\
\hline High school Graduate & $41.7 \%$ (905) & $47.6 \%(169)$ & $42.4 \%(338)$ & $38.2 \%(113)$ & $39.4 \%(285)$ \\
\hline$>$ High school & $24.5 \%(531)$ & $30.7 \%(109)$ & $18.6 \%(148)$ & $39.5 \%(117)$ & $21.7 \%(157)$ \\
\hline Unknown & $9.2 \%(199)$ & $3.7 \%(13)$ & $9.7 \%(77)$ & $6.4 \%(19)$ & $12.5 \%(90)$ \\
\hline \multicolumn{6}{|l|}{ Place of death } \\
\hline Inpatient & $24.9 \%(541)$ & $28.2 \%(100)$ & $22.6 \%(180)$ & $24.3 \%(72)$ & $26.1 \%(189)$ \\
\hline \multicolumn{6}{|c|}{ Contributory causes of death } \\
\hline \multicolumn{6}{|l|}{ Alzheimer's disease } \\
\hline Diabetes & $3.8 \%(82)$ & $2.3 \%(8)$ & $2.9 \%(23)$ & $4.4 \%(13)$ & $5.3 \%(38)$ \\
\hline
\end{tabular}

intermediate care facilities, ${ }^{12}{ }^{16}$ the nursing home category variable was included in the multilevel models.

The null model showed that very little variance in the no-transfer outcome was found at the individual nursing home level (4.4\%). After controlling for the nursing home characteristics as fixed effects, the variance explained at the nursing home level increased slightly to $4.8 \%$. Contrary to our hypotheses, for-profit status, level of nursing care, and QOC rating had no effect on the probability of no transport of nursing home residents with heart disease prior to death.

Adding decedent characteristics as fixed effects to the model reduced the nursing home level variance to $3.7 \%$. Age was a significant predictor of no transfer: the oldest decedents ( $\geq 100$ years old) were much more likely to not be transferred compared with decedents aged $60-69$ years $(\mathrm{OR}=5.92,95 \%$ CI 2.60 to 13.49$)$.
Significant associations with no transfer were also found for being unmarried $(\mathrm{OR}=1.38,95 \%$ CI 1.03 to 1.85$)$ and having less than a high school degree $(\mathrm{OR}=1.29$, $95 \%$ CI 1.02 to 1.65$)$. A senility-related contributory cause of death $(\mathrm{OR}=1.3995 \%$ CI 0.99 to 1.94$)$ and female gender $(\mathrm{OR}=1.2195 \%$ CI 0.97 to 1.50$)$ had borderline significant associations with no transfer prior to death. Blacks and Hispanics were much more likely than whites to be transferred prior to death ( $\mathrm{OR}=0.59,95 \%$ CI 0.41 to 0.87 ).

The full model included nursing home random intercepts and fixed effects for all nursing home and decedent characteristics. The findings were similar to those in the models that included only nursing home or decedent level fixed effects: being older, not currently married, or less educated was associated with a greater probability of dying without transfer, while 
Table 3 Multilevel models of nursing home $(n=131)$ and decedent $(n=2172)$ characteristics and no transport prior to cardiac death in the Tampa MSA, 1998-2002

\begin{tabular}{|c|c|c|c|c|}
\hline & $\begin{array}{l}\text { Null } \\
\text { model }\end{array}$ & $\begin{array}{l}\text { Nursing home } \\
\text { model } \\
\text { OR }(95 \% \mathrm{Cl})\end{array}$ & $\begin{array}{l}\text { Decedent model } \\
\text { OR }(95 \% \mathrm{Cl})\end{array}$ & $\begin{array}{l}\text { Full model } \\
\text { OR }(95 \% \mathrm{Cl})\end{array}$ \\
\hline \multicolumn{5}{|l|}{ Decedent level } \\
\hline Age $60-69$ years & & & 1.00 (Referent) & 1.00 (Referent) \\
\hline Age $70-79$ years & & & $1.80(1.08$ to 3.00$)$ & $1.83(1.09$ to 3.06$)$ \\
\hline Age $80-89$ years & & & 2.29 (1.42 to 3.68$)$ & 2.35 (1.45 to 3.79$)$ \\
\hline Age $90-99$ years & & & 4.07 (2.50 to 6.63$)$ & 4.17 (2.55 to 6.82$)$ \\
\hline Age $\geq 100$ years & & & 5.92 (2.60 to 13.49$)$ & 5.97 (2.61 to 13.66$)$ \\
\hline Male & & & 1.00 (Referent) & 1.00 (Referent) \\
\hline Female & & & $1.20(0.96$ to 1.49$)$ & $1.21(0.97$ to 1.50$)$ \\
\hline White & & & 1.00 (Referent) & 1.00 (Referent) \\
\hline Black or Hispanic & & & $0.59(0.41$ to 0.87$)$ & $0.58(0.40$ to 0.86$)$ \\
\hline Married & & & 1.00 (Referent) & 1.00 (Referent) \\
\hline Widowed/unmarried & & & $1.38(1.03$ to 1.85$)$ & 1.39 (1.03 to 1.86$)$ \\
\hline High school degree & & & 1.00 (Referent) & 1.00 (Referent) \\
\hline No high school degree & & & $1.29(1.02$ to 1.65$)$ & $1.29(1.01$ to 1.64$)$ \\
\hline $\begin{array}{l}\text { No mention of dementia, senility } \\
\text { or related conditions }\end{array}$ & & & 1.00 (Referent) & 1.00 (Referent) \\
\hline $\begin{array}{l}\text { Dementia, senility or related condition } \\
\text { Nursing home level }\end{array}$ & & & 1.39 (0.99 to 1.94$)$ & 1.38 (0.99 to 1.94$)$ \\
\hline Skilled NF-non-profit & & 1.00 (Referent) & & 1.00 (Referent) \\
\hline Skilled NF-for-profit & & $1.01(0.65$ to 1.57$)$ & & $1.08(0.71$ to 1.64$)$ \\
\hline Intermediate NF-non-profit & & $1.04(0.62$ to 1.74$)$ & & 1.06 (0.64 to 1.76$)$ \\
\hline Intermediate NF-for-profit & & $0.87(0.56$ to 1.36$)$ & & 1.01 (0.66 to 1.55$)$ \\
\hline \multicolumn{5}{|l|}{ Distance from $\mathrm{NH}$ to nearest hospital } \\
\hline$<2.5$ miles & & 1.00 (Referent) & & 1.00 (Referent) \\
\hline $2.5-5.0$ miles & & $0.88(0.65$ to 1.19$)$ & & $0.94(0.71$ to 1.27$)$ \\
\hline$>5.0$ miles & & $0.71(0.48$ to 1.04$)$ & & 0.68 (0.45 to 0.99$)$ \\
\hline Quality of care NH Rating (4, 5 best) & & 1.00 (Referent) & & 1.00 (Referent) \\
\hline Quality of care NH Rating (1, 2, 3 worst) & & $1.11(0.84$ to 1.45$)$ & & $1.15(0.88$ to 1.50$)$ \\
\hline $\mathrm{NH}$ variance (random effect) & 0.1511 & 0.1658 & 0.1256 & 0.1254 \\
\hline $\begin{array}{l}\text { Percentage of total variance at } \\
\mathrm{NH} \text { level (\%) }\end{array}$ & 4.4 & 4.8 & 3.7 & 3.7 \\
\hline-2 Res Log Pseudo-Likelihood & 9611.94 & 9626.00 & 9771.05 & 9785.50 \\
\hline
\end{tabular}

Blacks and Hispanics were less likely to die from heart disease without hospital transfer. However, contrary to our hypothesis, nursing homes located farther away from a hospital were more likely to transfer patients with heart disease prior to death $(\mathrm{OR}=0.68,95 \%$ CI 0.45 to 0.99 ).

\section{DISCUSSION}

Frail older people with multiple morbidities present many challenges in highly regulated nursing homes that provide room, board, $24 \mathrm{~h}$ nursing care, and other health and social services for under $\$ 150$ a day on average. In the USA, widespread problems in QOC in nursing homes have been identified. ${ }^{1}$ In our study population of elderly decedents in metropolitan nursing homes in Florida, over a third of cardiac decedents were residing in facilities with poor QOC ratings at the time of their deaths. Previous research has found that corporate for-profit ownership status and intermediate-level nursing care have resulted in lower QOC in nursing facilities. ${ }^{12} 13$ However, contrary to our hypotheses, we found that nursing home characteristics were not associated with the likelihood of a cardiac decedent being transferred prior to death. Distance to the nearest hospital was the only nursing home characteristic associated with no transfer, but contrary to what we hypothesised, decedents in nursing homes farthest away from a hospital were significantly more likely to be transferred prior to death. However, none of the nursing homes included in this analysis were in remote rural areas, therefore our findings may not be generalisable to other regions.

The few studies that have focused on transfer prior to cardiac death focused on decedents in noninstitutionalised populations, most of whom were aged 65 years and younger. In agreement with our current findings, these studies found that being unmarried increased the likelihood of no transfer, while being a racial/ethnic minority was protective against no transfer. $^{141718}$ However, contrary to previous findings, ${ }^{1417} 18$ 
we found that nursing home resident cardiac decedents with lower educational attainment were less likely to be transferred prior to death.

One previous study examined the demographic characteristics associated with in-hospital death among Medicare-eligible and Medicaid-eligible Florida nursing home decedents who died during 2000-2002. ${ }^{19}$ This study also found that older age was a predictor of dying outside of the hospital, and black race reduced the risk of dying out of hospital. ${ }^{19}$ Similar to our results, dementia as the principal cause of death was also a significant predictor of dying outside of the hospital in Flanders, Belgium. ${ }^{18}$ Previous research has shown that a nursing home resident's primary clinical diagnosis (ie, the medical reason for nursing home admission) is an important factor in the decision to hospitalise; residents who were cognitively impaired ${ }^{10}$ or had a primary diagnosis of dementia or schizophrenia were less likely to be hospitalised than residents with a primary diagnosis of ischaemic heart disease or congestive heart failure. ${ }^{11}$

Consistent with previous research, older age was the strongest predictor of no transfer prior to death in our study. Almost half of the decedents in our study were ages 90 years or older at the time of death. Having a life expectancy of less than 3 months significantly reduces the likelihood of hospitalisation. ${ }^{20}$ As older residents have shorter life expectancies, nursing home staff may initiate transfer for these residents less frequently presuming that they are less likely to benefit from treatment. The transfer to a hospital can also be traumatic to a resident, and a decline in QOL resulting from hospitalisation has been cited by physicians as an important factor in the decision not to hospitalise residents. ${ }^{20}$

No transfer was also more likely among decedents who were unmarried. Resident and family preferences for care have been identified as important considerations by nursing home staff in deciding whether to hospitalise a resident. ${ }^{21}$ The residents who are currently married may be viewed by nursing home staff as having active family involvement. In turn, family members may be more likely to insist on more aggressive medical care, including hospitalisation. Taking the initiative of transferring a resident with heart disease may also represent an effort to avoid postmortality malpractice suits by the next of kin. ${ }^{21}$

The most important influence on the decision to transfer nursing home residents at the end of life may be DNR or DNH orders. However, as mentioned earlier, only a minority of nursing home residents in the USA have these orders in place. ${ }^{20}$ The fact that Blacks and Hispanics are less likely to have a DNR or DNH order ${ }^{8} 16$ or utilise hospice care $^{18}$ is a possible explanation for the racial/ethnic differences in hospital transfer found in our study. Had we controlled for the presence of a DNH or DNR order, our protective finding for Black/Hispanic race/ethnicity may have been attenuated. We did not have data on whether these cardiac decedents had advanced directives in place; therefore, further research is needed to assess what factors account for these observed ethnic differences in transfer status.

Although nursing home characteristics were not significant predictors of no transfer prior to heart disease death in our study, previous research on hospitalisation of nursing home residents for any reason found some associations with facility characteristics. Nursing homes that were non-profit, had more beds, and had a higher proportion of total patient-days reimbursed by Medicare were less likely to hospitalise residents. ${ }^{11}$ Corporate forprofit chain ownership, a lower proportion of nursing staff who were more highly qualified RNs, rather than licensed practical nurses (LPNs), and a high proportion of residents whose care was reimbursed by Medicaid were associated with more frequent hospitalisation. ${ }^{11}$

Previous literature has suggested that nursing home staffing can influence the level and QOC that can be provided. As we did not have data on staffing patterns such as the number of LPNs, RNs or physicians on staff at each facility, we could not examine whether having a higher ratio of RNs to LPNs, for example, would be associated with a greater likelihood of not being transferred to a hospital before death. We were also not able to consider resident care preferences in our analyses. Future research on the predictors of no transport prior to heart disease death should include more information on the clinical histories of decedents and the staffing characteristics of the nursing home that decedents resided in.

Our results are limited to nursing home residents who died of heart disease. Other than the contributory causes of death indicated on the death certificate, we did not have data on comorbid clinical conditions that may have influenced the decision to transfer a decedent. Health characteristics that have been found to be significant predictors of hospitalisation of nursing home residents include greater physical disability and clinical conditions such as congestive heart failure, circulatory problems, respiratory problems and infection. ${ }^{22}$ Consistent with our finding of a marginally significant association between a dementia or senility-related condition and death prior to transfer, previous studies have found that residents with dementia are less likely to be hospitalised. ${ }^{22}$ This finding may be partially explained by previous research that found that the majority of nursing home residents with advanced dementia have a DNH order. ${ }^{23}$ The same study also found that the next of kin of severely demented residents are less likely to choose aggressive treatment options, including hospitalisation. ${ }^{23}$

Although we did not find facility characteristics to be significant predictors of transport prior to cardiac death, future studies should examine additional nursing home characteristics such as the RN/LPN staffing ratio, occupancy rate and the availability of hospice care within the nursing home. Our results showed that decedent characteristics were significant predictors of whether a nursing home resident was transferred prior to heart disease death. Future research should focus on whether 
nursing home patient hospital transfer decisions at the end of life are consistent with patient and family preferences.

Acknowledgements The authors would like to thank Dr Steven Reader and Dr Beverly Ward for their contributions to the original geocoding of the decedent data analysed in this study.

Contributors EBP conceived the study. GMA, JPT and EBP acquired and analysed the data. GMA drafted the manuscript. All authors contributed to the design and methods; the interpretation and discussion of results; and the editing and final form of the manuscript.

\section{Funding ASPH/CDC Cooperative Agreement S3026/}

Competing interests This research was funded by a cooperative agreement from the Centers for Disease Control and Prevention (CDC), administered through the Associations of Schools of Public Health (ASPH). The authors submitted the manuscript for scientific 'clearance' review and approval at the $\mathrm{CDC}$, as required by MLC's co-authorship, which resulted in some minor edits for clarity and format.

Provenance and peer review Not commissioned; externally peer reviewed.

Data sharing statement The data analysed for this study are publicly available death certificate data.

Open Access This is an Open Access article distributed in accordance with the Creative Commons Attribution Non Commercial (CC BY-NC 3.0) license, which permits others to distribute, remix, adapt, build upon this work noncommercially, and license their derivative works on different terms, provided the original work is properly cited and the use is non-commercial. See: http:// creativecommons.org/licenses/by-nc/3.0/

\section{REFERENCES}

1. Institute of Medicine. Improving the quality of long-term care. In: Wunderlich GSKohler PO, eds. Committee on Improving Quality in Long-Term Care, Division of Health Care Services, Washington, DC: National Academy Press, 2001.

2. Kung HC, Hoyert DL, Xu JQ, et al. Deaths: final data for 2005. National vital statistics reports; vol 56 no. 10. Hyattsville, MD: National Center for Health Statistics, 2008.

3. Aronow WS. Heart disease and aging. Med Clin North Am 2006;90:849-62.

4. National Institutes of Health. Morbidity and mortality: 2007 chart book on cardiovascular, lung and blood diseases. Bethesda, MD: National Institutes of Health National Heart, Lung, and Blood Institute, 2007.

5. Bach RG, Cannon CP, Weintraub WS, et al. The effect of routine, early invasive management on outcome for elderly patients with
non-ST-segment elevation acute coronary syndromes. Ann Intern Med 2004;141:186-95.

6. Søholm H, Bro-Jeppesen J, Lippert FK, et al. Resuscitation of patients suffering from sudden cardiac arrests in nursing homes is not futile. Resuscitation 2014;85:369-75.

7. Dobalian A. Nursing facility compliance with do-not-hospitalize orders. Gerontologist 2004;44:159-65.

8. Levy CR, Fish R, Kramer A. Do-not-resuscitate and do-nothospitalize directives of persons admitted to skilled nursing facilities under the Medicare benefit. J Am Geriatr Soc 2005;53:2060-8.

9. Jones A. The National Nursing Home Survey: 1999 summary. National Center for Health Statistics. Vital Health Stat 13 2002:1-116.

10. Intrator O, Castle NG, Mor V. Facility characteristics associated with hospitalization of nursing home residents: results of a national study. Med Care 1999;37:228-37.

11. Carter MW, Porell FW. Variations in hospitalization rates among nursing home residents: the role of facility and market attributes. Gerontologist 2003;43:175-91.

12. O'Neill C, Harrington C, Kitchener M, et al. Quality of care in nursing homes: an analysis of relationships among profit, quality, and ownership. Med Care 2003;41:1318-30.

13. Harrington C, Woolhandler S, Mullan J, et al. Does investor ownership of nursing homes compromise the quality of care? Am J Public Health 2001;91:1452-5.

14. Barnett E, Reader S, Ward BG, et al. Social and demographic predictors of no transport prior to premature cardiac death: United States 1999-2000. BMC Cardiovasc Disord 2006;6:45-55.

15. U.S Bureau of the Census, Census 2000.

16. Dobalian A. Advance care planning documents in nursing facilities: results from a nationally representative survey. Arch Gerontol Geriatr 2006;43:193-212.

17. Sorlie PD, Coady S, Lin C, et al. Factors associated with out-ofhospital coronary heart disease death: the national longitudinal mortality study. Ann Epidemiol 2004;14:447-52.

18. Van Rensbergen G, Nawrot TS, Van Hecke E, et al. Where do the elderly die? The impact of nursing home utilisation on the place of death. Observations from a mortality cohort study in Flanders. BMC Public Health 2006;6:178.

19. Kwak J, Haley WE, Chiriboga DA. Racial differences in hospice use and in-hospital death among Medicare and Medicaid dual-eligible nursing home residents. Gerontologist 2008;48:32-41.

20. Buchanan JL, Murkofsky RL, O'Malley AJ, et al. Nursing home capabilities and decisions to hospitalize: a survey of medical directors and directors of nursing. J Am Geriatr Soc 2006;54:458-65.

21. Cohen-Mansfield J, Lipson S. To hospitalize or not to hospitalize? That is the question: an analysis of decision making in the nursing home. Behav Med 2006;32:64-70.

22. Grabowski DC, Stewart KA, Broderick SM, et al. Predictors of nursing home hospitalization: a review of the literature. Med Care Res Rev 2008;65:3-39.

23. Maust DT, Blass DM, Black BS, et al. Treatment decisions regarding hospitalization and surgery for nursing home residents with advanced dementia: the CareAD Study. Int Psychogeriatr 2008;20:406-18. 